DOI: https://doi.org/10.24867/03DS06Mudrinic

\title{
STRATEGIJE KOLABORACIJE U LANCIMA SNABDEVANJA SA OSVRTOM NA TRANSPORT
}

\section{COLLABORATION STRATEGIES IN SUPPLY CHAINS WITH A REVIEW ON TRANSPORT}

\author{
Saša Mudrinić, Fakultet tehničkih nauka, Novi Sad
}

\begin{abstract}
Oblast - SAOBRAĆAJ
Kratak sadržaj - Kolaboracija je relativno nov pojam $u$ terminologiji logistike $i$ upravljanja lancima snabdevanja pa samim tim $i$ nedovoljno istražena, a još manje primenjena u praktičnom okruženju. Zbog svoje složenosti, kolaboraciju nije moguće uvek primeniti na svakom modelu poslovanja. Iz tog razloga kolaboracija se sa pravom može nazvati višim stepenom logističkog upravljanja. Osnovni cilj ovog rada je locirannje $i$ shvatanje značaja kolaboracije u lancima snabdevnja kao i prepoznavnje ukupnih dobiti koje kolaboracija doprinosi zinteresovanim stranama sa posebnim osvrtom na značaj kolboracije u transportu.
\end{abstract}

Ključne reči: Lanci snabdevanja, Kolaboracija, Transport

Abstract -Collaboration is a relatively new concept in the terminology of Logistics and Supply Chain Management, and thus insufficiently explored, and even less applied in a practical environment. Due to its complexity, collaboration can't always be applied to every model of business. For this reason, collaboration can rightly be called a higher degree of logistic management. The main goal of this paper is to locate and understand the importance of collaboration in Supply Chains as well as to identify the total benefits that the collaboration contributes to the interested parties, with special review on the importance of collaboration in transport.

Keywords: Supply Chains, Collaboration, Transport

\section{UVOD}

Da bi kompanije uspele odgovoriti na zahteve klijenata i opstale na tržištu, između ostalog, od presudne je važnosti logističko upravljanje. Danas je nezamislivo upravljanje bilo koje kompanije bez čvrstih osnova lanca snabdevanja. Razvijene kompanije su odavno uspele da svoje logističke operacije kao što su utovar, istovar, skladištenje robe, transport, proizvodni procesi dovedu do perfektne optimizacije i samim tim uštede na svim značajnim nivoima, a pre svega u novcu i vremenu. Sada su pred njih postavljeni novi ciljevi razvoja, ili se može reći da su one same kreirale i nametnule te nove ciljeve $u$ lancima snabdevanja.

\footnotetext{
NAPOMENA:

Ovaj rad proistekao je iz master rada čiji mentor je bio doc. dr Marinko Maslarić.
}

Iako su velike kompanije gledano pojedinačno samostalne i nezavisne, nisu u mogućnosti da same oblikuju tržište, zbog čega su prinuđene da sarađuju sa raznim drugim kompanijama. Da bi postale uspešnije međusobno se udružuju zarad zajedničkih interesa. Ovakav tip planskog udruživanja unutar lanca snabdevanja na najvišem nivou upravljanja, gde se razmenjuje znanje, informacije, infrastrukturni objekti i ljudski resursi predstavlja kolaboraciju. Sa pravom se može reći da kolaboracija predstavlja najviši stepen integracije.

\section{UPRAVLJANJE LANCIMA SNABDEVANJA}

Kada se termin logistika izborio za pravo naziva kojim se pokriva integrisano upravljanje, planiranje i kontrola (svih) aktivnosti povezanih sa kompletnim protokom proizvoda od njegovog izvora do krajnjeg cilja, pojavljuje se novi termin - upravljanje lancima snabdevanja (eng. Supply Chain Management - SCM). Ovaj termin dovodi do nesuglasica obzirom da je jedna grupa autora smatrala da termin logistika nije dovoljno širok, dok druga grupa autora smatra da je to samo faza evolucije već poznatog koncepta logistike. Larson i Halldorssonu su identifikovali četiri moguća odnosa logistike i upravljanja lancima snabdevanja što je prikazano na slici 1 .

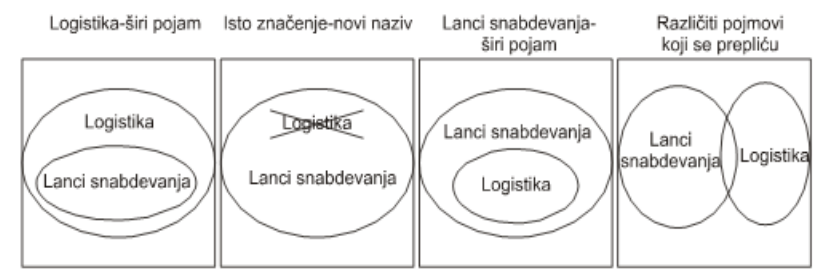

Slika 1. Različiti odnosi logistike i upravljanja lancima snabdevanja [1]

Osnovni razlog ovakvog različitog posmatranja odnosa logistike i upravljanja lancima snabdevanja jeste činjenica da ih nije moguće predstaviti preko jedne univerzalne definicije.

\subsection{Definicije logistike i upravljanja lancima snabdevanja}

Neprofitna poslovna organizacija za upravljanje lancima snabdevanja - CSCMP (eng. Council of Supply Chain Managment Professionals) definiše logistiku na sledeći način:

„Logistika je deo upravljanja lancem snabdevanja koji obuhvata proces planiranja, $i$ kontrole efikasnih $i$ troškovno-efektivnih tokova materijala, skladištenja robe, usluga $i$ njima pripadajucih informacionih tokova od 
mesta izvora do mesta potrošnje sa ciljem zadovoljenja zahteva krajnjih korisnika“.

Institut za logistiku i transport daje definiciju logistike u kojoj se kaže da je 'logistika proces upravljanja transportom, zalihama, skladištenjem i informacijama o dobrima $i$ materijalima od izvora do mesta finalne potrošnje'. Značaj ove definicije je što u sebi inkorporira četiri najveća i najvažnija podsistema logistike: transport, zalihe, skladištenje i informacije. Logistika se često definiše kroz koncept „7P" , koji podrazumeva:

- pravu robu;

- u pravo vreme;

- $\quad$ na pravom mestu;

- u pravoj količini;

- $\quad$ po pravoj (najboljoj) ceni;

- $\quad$ pravog kvaliteta;

- $\quad$ stigne do pravog (odgovarajućeg) kupca.

Lanac snabdevanja predstavlja mrežu organizacija koje su uključene $\mathrm{u}$ određene procese $\mathrm{i}$ aktivnosti kojima se uvećavaju vrednosti njihovih proizvoda i usluga sa aspekta krajnjih potrošača, čiji su fizički entiteti: snabdevači, proizvođači, distributeri, maloprodaje. Upravljanje egzekutivnim delom i oblikovanje fiksnog dela lanca snabdevanja čine zajedno upravljanje lancem snabdevanja [1].

\subsection{Koordinacija u lancima snabdevanja}

Koordinacija se definiše kao harmonično funkcionisanje delova celine koja daje efektivne rezultate čija je svrha ostvarivanje ukupnih (kolektivnih) ciljeva koje individualni učesnici sami ne mogu ostvariti. Koordinacija u lancu utiče pozitivno na smanjenje neizvesnosti u lancima što doprinosi i smanjenju varijabilnosti koja predstavlja osnovni uzrok nastajanja nepotrebnih troškova. Pojava povećanja varijabilnosti potražnje pri pomeranju od maloprodaje ka višim (upstream) delovima lanca snabdevanja naziva se efekat biča (eng. bullwhip effect) i prikazan je na slici 2 .

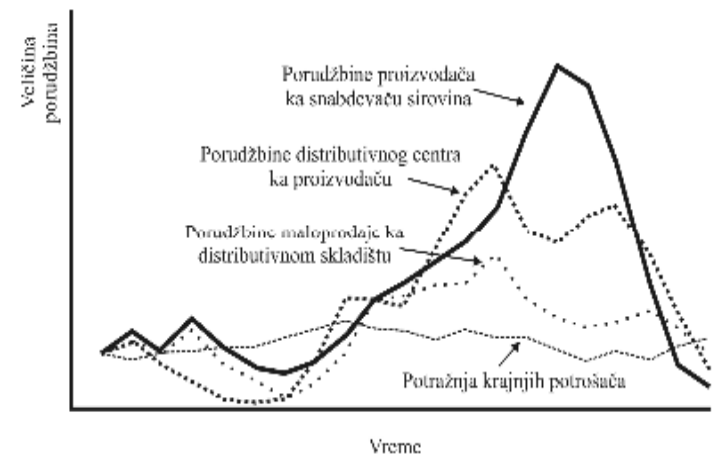

Slika 2. Efekat biča [1]

\section{STRATEGIJE KOLABORACIJE U LANCIMA SNABDEVANJA}

Poslednjih godina logističko udruživanje - pooling dobija neverovatnu ekspanziju. Efikasnost logističkih sistema je i dalje nedovoljno razvijena i postoji veliki potencijal za poboljšanja $u$ ovom sektoru. Rezultati tradicionalnih logističkih šema objašnjavaju potrebu da se razvijaju i druge strategije za stvaranje novih efikasnijih logističkih sistema, kao što je kolaborativna logistika [2]. Saradnja se dešava kada najmanje dve strukture odluče da razmene fizičke i/ili informativne resurse za donošenje odluka ili ostvarivanje aktivnosti za stvaranje profita [3]. Postoje dva osnovna tipa kolaboracije u lancima snabdevanja, a to su horizontalna i vertikalna kolaboracija, prikazane na slici 3 .

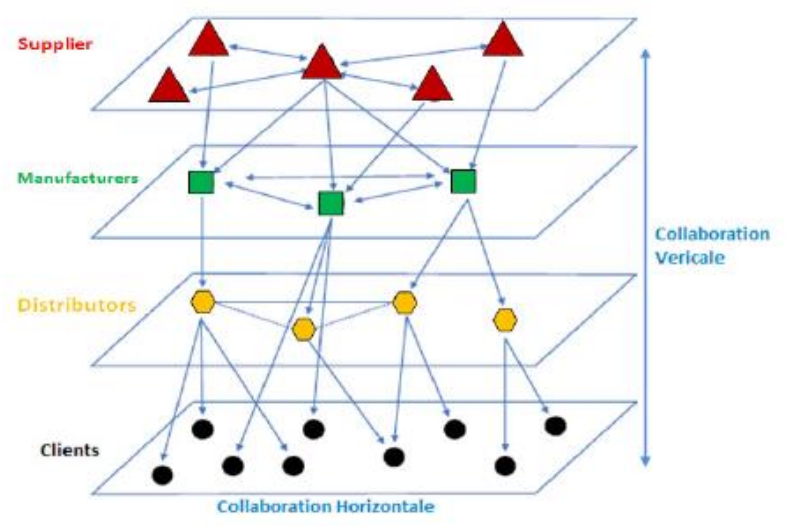

Slika 3. Tipovi kolaborativne logistike [2]

\subsection{Definicija poolinga}

Po definicji, pooling u lancima snabdevanja sastoji se od nekoliko nezavisnih firmi koje dele (̌̌eruju, zajednički realizuju) logističke aktivnosti. Pooling se može implementirati na različitim nivoima lanca snabdevanja, može se pojaviti među maloprodajnim trgovcima, između velikih industrija ili između malih i srednjih preduzeća. Može biti između subjekata upstream forme (primer između industrije hrane i maloprodaje) ili između subjekata downstream forme u urbanoj logistici [4].

\subsection{Vrste poolinga}

U svom istraživanju "Tipologija logističkog poolinga $u$ lancima snabdevanja" [4] definišu četri tipa poolinga:
1. "Klub" pooling.
2. Dominacijski pooling.
3. Lokalni pooling.
4. Politički pooling.

Prva vrsta strategije je "klub" pooling, koji okuplja firme iz istog sektora, koji odlučuju da udruže svoje logističke resurse za snabdevanje maloprodaje istom distributivnom mrežom. Generalno, uključen je ograničen broj (ispod deset) velikih konkurentskih firmi. $\mathrm{Da}$ bi pooling funkcionisao nepohodno je da je da firme shvate da su, iako su konkurenti, u zajedničkom interesu da svoje logističke operacije udružuju.

Drugi tip poolinga je "dominacijski" koji okuplja brojne firme iz istog sektora, gde su pojedini trgovci (maloprodaja) primorani da dele deo svoje logistike. Ovde su su pitanju uglavnom male ili veoma male firme kojima je teško da odgovore na logističke zahteve maloprodaje. Dominacijski pooling je iniciran i koordinisan od strane maloprodaje, ali koristi provajdere logističkih usluga čija je funkcija uglavnom ograničena na operativnom nivou upravljanja.

Treći tip poolinga je lokalna strategija i ona okuplja firme koje se međusobno nalaze u blizini. Ove firme se odlučuju za udruživanje svojih logističkih resursa da usluže iste maloprodajne sisteme. Ovaj pooling generalno 
obuhvata mali broj (nekoliko desetina) srednjih, malih ili veoma malih firmi koje ne moraju nužno biti $\mathrm{u}$ istom sektoru.

Poslednji tip je politički pooling, a okuplja maloprodajne sisteme na istom području koje su lokalne vlasti ograničile da udruže svoju logistiku. Ove maloprodaje su obično mali trgovci koji zbog svoje veličine nisu $u$ mogućnosti da preuzmu isporuke velikog obima. Zbog ove nesposobnosti lokalna vlast zahteva od malih pojedinaca da koriste zajedničku platformu koja sabira njihove isporuke.

\subsection{Koristi kolaboracije u lancima snabdevanja}

Kompanijama uspešni odnosi u lancu snabdevanja znače mnogo više od troškovne efikasnosti i ekonomskih pogodnosti. Dobra i uspešna kolaboracija donosi sa sobom i druge važne prednosti koje nisu uvek očigledne, pa ih često i najviši menadžment kompanije teško ili sporo uočava. Prednosti se postižu na brojne načine tokom životnog veka kolaboracije; povećanjem obima prodaje, smanjenjem operativnih troškova, razmenom informacija, novim proizvodnim i procesnim inovacijama u radnom odnosu između partnera koji imaju međusobno poverenje.

Kako se odnosi u lancu snabdevanja produžuju u vremenu, a ukoliko je kolaboracija uspešna, ukupne koristi će rasti. Međutim, koristi partnera ne moraju rasti istim procentima. Drugim rečima, neki od partnera unutar kolaboracije mogu imati veće koristi od iste i brži napredak. Upravo nerazumevanje ove pojave često dovodi do zaoštravanja odnosa između partnera. Sa druge strane, zbog nerealnih očekivanja obeju strana, inače profitabilni odnosi se mogu pogoršati. Ovo se naziva problem apsolutnih i relativnih dobitaka. Jasno je da se ove koristi se ne mogu u potpuno jednakim delovima raspodeliti partnerima. Ali sve dok partnerstvo bude uzajamno korisno i jača konkurentsku poziciju lanca snabdevanja u celini, sve stranke bi trebalo da steknu značajne koristi u apsolutnom smislu.

\section{POOLING U AKTIVNOSTIMA TRANSPORTA}

Tradicionalno, polje transporta robe se često posmatra kao varijabla prilagođavanja za planiranje i upravljanje logistikom. U proteklim godinama, prevoz ima još jednu dimenziju, jer nekoliko radova pokazuje važnost uključivanja u odluke o upravljanju lancima snabdevanja. Transportni modeli su kompleksni sistemi koje treba definisati i detaljno proučiti.

\subsection{Višestepeni transport i upravljanje lancima snabdevanja}

Novi napredak u tehnologiji je bio pozitivan faktor za razvoj novih tržišta i novih zahteva potrošača, koji imaju direktan uticaj na planiranje i upravljanje logistikom. Ovo je istaklo važnost uključivanja upravljanja transportom u planiranje lanca snabdevanja i u pitanja upravljanja najvišeg menadžmenta. Međutim, da bi transportni sistem bio integrisan u lanac snabdevanja, važno je prvo da se definišu i identifikuju njegove glavne varijable i ograničenja, tj. da se modeluje.

Višestepene transportne sisteme karakteriše jedna ili više grupa posredničkih nivoa. U ovim posredničkim objektima se odvijaju operacije kako bi se pomogao proces distribucije, smanjili troškovi, pružio veći kvalitet usluge ili ponudile neke dodatne usluge vozačima. U većini slučajeva višestepenog transporta, glavne karakteristike su povezane sa promenom vozila najmanje $\mathrm{u}$ jednom posredničkom terminalu. U ovim posredničkim terminalima teret se reorgnizuje a zatim sledi utovar na vozila. Osnovne više-stepene transportne strategije prikazne su na slici 4 .

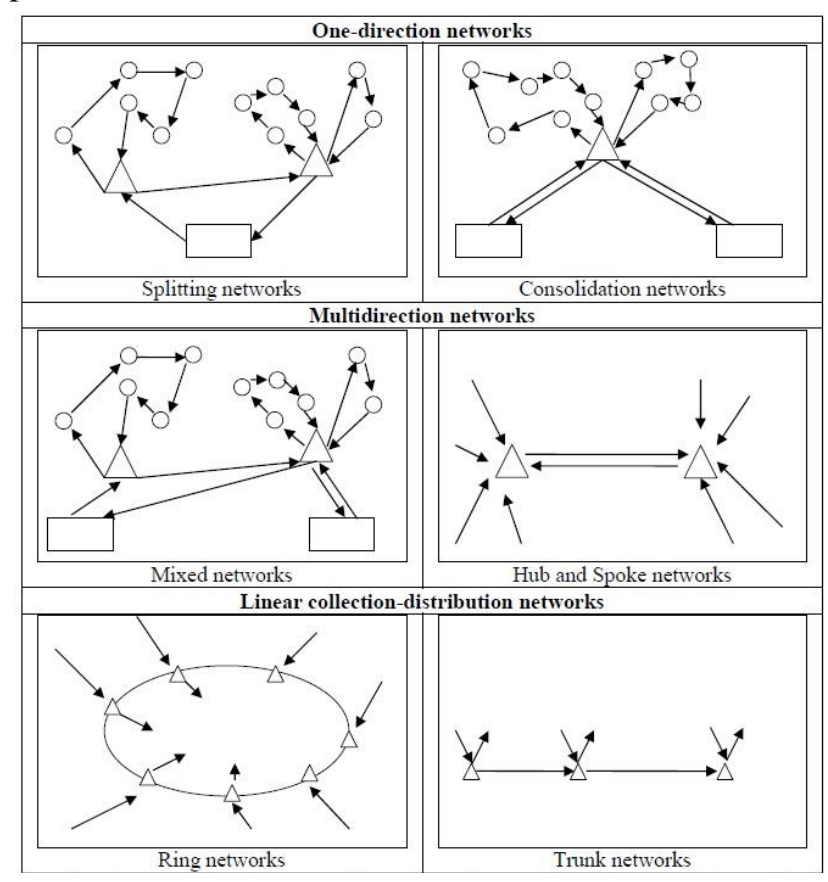

Slika 4. Osnovne više-stepene transportne strategije [5]

\subsection{Planiranje, upravljanje i optimizacija višestepenih LTL transportnih sistema}

U planiranju i upravljanju distrbutivnom logistikom, odluke o modelima prevoza i njihova efikasnost imaju direktan uticaj i na operativne troškove i na kvalitet usluga. Shodno tome, važno je prilagoditi transportne mreže različitoj logistici i teritorijalnim preprekama bez zaboravljanja njihovih veza sa lancem snabdevanja i upravljačkim akcijama unutar organizacije. Višestepeni transportni sistemi predstavljaju poteškoće u upravljanju dva ili više modela transporta gde treba sprovoditi crossdocking i sinhronizaciju. Planovi operativnog i izvršnog planiranja se bave odlukama $u$ kratkom i realnom vremenu koje treba dobro fokusirati na pojedinačne operacije i njihove unutrašnje organizacije

\section{STUDIJA SLUČAJA}

U okviru studije slučaja predstavljen je praktičan primer u organizaciji transporta u kompaniji IK Speditor doo, iz Novog Sada. U pitanju je međunarodni transport robe $u$ zbirnom transportu na relaciji 65527 Niedernhausen, Nemačka - 11000 Beograd - 22400 Bačka Palanka. Vrsta robe koja se transportuje su štamparske boje, dok je količina 6 IBC kontejnera dimenzija 120x100x118 cm i 2 euro palete dimenzija 120x80x200 cm sa bruto kilažom od $4.760 \mathrm{~kg}$. Početak transportnog procesa predstavlja upit za transport upućen od strane komitenta ka IK Speditoru. Logistički opetater zaposlen u IK Speditoru obrađuje upit sa svim relevantnim podacima i kreće u 
organizaciju transporta. U navedenom slučaju u pitanju je FCA Niedernhausen paritet isporuke. Obzirom da se radi o zbirnom transportu, potrebno je odrediti koliko roba zauzima ukupno prostora na kamionu i u ovom slučaju to je 3,8 utovarnih metara - LDM (6 x $0.5 \mathrm{LDM}+2 \times 0.4$ LDM).

Pre preuzimanja robe u Nemačkoj, logistički operater inodobavljačima najavljuje utovar što podreazumeva: broj kamiona, ime i prezime vozača, broj pasoša, datum preuzimanja robe i izlazno mesto iz Evropske unije. Situacija se dodatno komplikuje u zbirnom transportu ukoliko unapred nije poznat raspored svih utovarnih mesta već se tokom odlaska na ugovoreno mesto utovara ujedno pronalaze i dodatne mogućnosti utovara za druge komitente, što se dešava u najvećem broju slučajeva. Nakon utovara vozač dobija dokumentaciju koja prati robu, a tu spada: faktura od robe, MRN dokument, EUR1 jer je roba Evropskog porekla i po izboru lista pakovanja. Po pristizanju u Beograd gde je mesto uvoznog carinjenja, roba se istovara u carinski magcin. Nakon završetka uvoznog carinjenja, roba je u slobodnom prometu i može da se isporuči do krajnjeg korisnika robe u Bačkoj Palanci.

\section{ZAKLJUČNA RAZMATRANJA}

Kompanije koje su dostigle visoke stepene razvoja mogu da primene strategije kolaboracije $u$ potpunosti $\mathrm{i}$ da njenom implementacijom očekuju određene dobiti koje se pre svega ogledaju kroz uštede tj optimizacije kao što su: smanjenje ukupnih logističkih troškova, uštede u vremenu, ljudskim resursima, infrastrukturnim objektima, itd. Kolaboracija je prisutna kod malih i srednjih preduzeća takođe, ali je njima teže da ostvare pune efekte kolaboracije. Kolaboracija predstavlja tip planskog udruživanja unutar lanca snabdevanja na najvišem nivou upravljanja, gde se razmenjuje znanje, informacije, infrastrukturni objekti i ljudski resursi.

Kolaboraciju nije uopšte jednostavno primeniti i ne treba je poistovećivati sa klasičnim tipovima saradnje između kompanija, jer ona predstavlja složen sistem gde svaki proces mora biti jasno definisan i pravilno implementiran. S obzirom na svoju prirodu, kolaboracija može da dovede i do konflikta između kompanija, jer neke kompanije mogu da se osećaju kao oštećene jer imaju ili smatraju da imaju manje koristi od svojih partnera $\mathrm{i}$ da sebe vide $\mathrm{u}$ nepovoljnijem položaju. Da bi se ovi problemi razumeli i premostili, značajne faktore predstavljaju pojmovi horizontalne i vertikalne kolaboracije.
Strategije kolaboracije su opisane kao složen sistem gde su prikazane teorijske osnove rada ovog sistema uopšteno. Pravci daljih istraživanja ogledaju se na dubljoj analizi i razvijanju pojedinih delova ovog sistema.

Potrebno je posebno posmatrati strategije kolaboracije u sektoru proizvodnje, distribucije, skladištenja, maloprodaje.

U tom slučaju bilo bi moguće napraviti više univerzalnih modela koje bi kompanije lakše mogle da implementiraju. Ovo bi naročito bilo značajno za mala i srednja preduzeća, koja su u ovom trenutku u nepovoljnijem položaju jer imaju manje raspoloživih resursa u odnosu na razvijena preduzeća.

\section{LITERATURA}

[1] Maslarić, M., Osnove upravljanja lancima snabdevanja - skripte sa predavanja, Fakultet tehničkih nauka, Novi Sad, 2016.

[2] Cruijssen, F.: Horizontal cooperation in transport and logistics, PhD thesis. Tilburg, Nederland 2006.

[3] Audy, J.-F., Lehoux, N., D’Amours, S., Ronnqvist, M.: A framework for an efficient implementation of logistics collaborations. International Transactions in Operational Research18. (2011)

[4] Rouquet, A., Vauche, L., A Typology of Logistics Pooling, Supply Chain Forum: An International Journal, 16 (2), 2016.

[5] Gonzalez-Feliu, J., Multi-stage LTL transport systems in supply chain management, Laboratoire d'Economie des Transports, Lyon, 2013.

\section{Kratka biografija:}

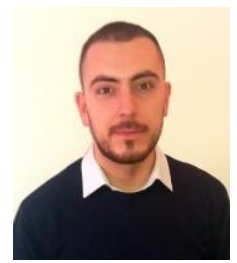

Saša Mudrinić rođen je u Somboru 1993. god. Osnovne akademske studije završio je 2016. godine na Fakultetu tehničkih nauka u Novom Sadu na Departmanu za saobraćaj, smer Saobraćaj i transport. Oblasti interesovanja: lanci snabdevanja,transport, logistika.

Kontakt: sasa.m.apa@gmail.com 